\title{
Optimizing Tip Diameter in Phacoemulsification of Varying Lens Sizes: An in vitro Study
}

\author{
Aniket Ramshekar $\mathbb{D}^{1,2}$ \\ Joshua Heczko (D) \\ Ashlie Bernhisel (iD) \\ William Barlow Jnr (D) \\ Brian Zaugg (D) \\ Randall Olson (iD) \\ Jeff Pettey (D)' \\ 'Department of Ophthalmology and \\ Visual Sciences, John A. Moran Eye \\ Center, University of Utah, Salt Lake City, \\ UT, 84I32, USA; ${ }^{2}$ University of Utah \\ School of Medicine, Salt Lake City, UT, \\ 84132, USA
}

Purpose: We assessed the effect of two lens cube sizes, three tip sizes, and two ultrasound (US) approaches on phacoemulsification efficiency and chatter.

Methods: After porcine lens nuclei were soaked in formalin, we divided them into cubes measuring $2.0 \mathrm{~mm}$ or $3.0 \mathrm{~mm}$. We collected efficiency and chatter data for 30-degree bent 19 G, $20 \mathrm{G}$, and $21 \mathrm{G}$ tips with a continuous torsional US system; and for straight $19 \mathrm{G}, 20 \mathrm{G}$, and $21 \mathrm{G}$ tips with a micropulse longitudinal US system.

Results: The average time needed for removal was always higher for the $3.0 \mathrm{~mm}$ lens cube than for the $2.0 \mathrm{~mm}$ lens cube. Statistically significant differences were observed between the $19 \mathrm{G}$ and $21 \mathrm{G}$ tips with micropulse longitudinal US using a $2.0 \mathrm{~mm}$ cube and a $3.0 \mathrm{~mm}$ cube, and with continuous transversal US using a $2.0 \mathrm{~mm}$ lens cube and a $3.0 \mathrm{~mm}$ cube. We did not observe significant differences between $19 \mathrm{G}$ and $20 \mathrm{G}$ tips with either cube size in either US system. However, we noted identical trends for both cube sizes with both US approaches; $19 \mathrm{G}$ tips performed better than $20 \mathrm{G}$ and $21 \mathrm{G}$ tips.

Conclusion: Regardless of the lens size, $19 \mathrm{G}$ needles were the most efficient, and had both the fewest outliers and the smallest standard deviations.

Keywords: cataract, chatter, efficiency, tip diameter, vacuum

\section{Plain Language Summary}

Phacoemulsification (phaco) allows for safe removal of cataractous lenses before insertion of a replacement lens. However, continued optimization of this technique is necessary to improve surgical outcomes. In this study, we compared two lens sizes, three phaco tips, and two ultrasound (US) approaches. Our team felt there could be a relationship between lens fragment size and tip bore diameter to potentially limit the efficiency benefit of a larger bore.

Using techniques we previously developed, we cut pig lenses into 2.0 and $3.0 \mathrm{~mm}$ cubes. We determined the efficiency and chatter for 30-degree bent $19 \mathrm{G}$ tips, as well as tips that were $20 \mathrm{G}$ and $21 \mathrm{G}$, with either micropulse longitudinal ultrasound or continuous torsional ultrasound.

Consistent with our hypothesis, we found higher mean removal times with the $3.0 \mathrm{~mm}$ lens cube for each of the ultrasound variations and for all the tips. We observed no efficiency superiority with $20 \mathrm{G}$ tips compared to $19 \mathrm{G}$ tips, especially with $3.0 \mathrm{~mm}$ cubes. For continuous transversal US, we found that $19 \mathrm{G}$ tips were more efficient than $20 \mathrm{G}$ tips. We noted significantly more chatter when removing $3.0 \mathrm{~mm}$ cubes using a $19 \mathrm{G}$ needle in micropulse longitudinal US compared to both $2.0 \mathrm{~mm}$ and $3.0 \mathrm{~mm}$ cubes with 20 and 21 $\mathrm{G}$ tips. Interestingly, we noted increased chatter with $3.0 \mathrm{~mm}$ cubes using $19 \mathrm{G}$ needles in micropulse longitudinal US.

Our findings about these previously unknown relationships are important for establishing an optimal balance between efficiency, wound size, and safety. 


\section{Introduction}

Phacoemulsification (phaco) technology is utilized in modern day cataract surgery to emulsify and aspirate the lens of the eye, to replace aspirated fluids with irrigation of balanced salt solution, and to maintain the integrity of the anterior chamber. ${ }^{1}$ In order to successfully complete a cataract surgery, selection of optimal settings to balance fluidics and ultrasound (US) power, appropriate phaco tip size, and design are vital.

A previous study from our laboratory evaluated the impact of phaco tip angles and phaco tip diameters on the efficiency of removing a $2 \mathrm{~mm}$ lens fragment. ${ }^{2}$ However, the average cataractous lens is approximately $5 \mathrm{~mm}$ anteroposteriorly and $9 \mathrm{~mm}$ equatorially; ${ }^{3}$ and once the lens is segmented into quadrants, the resulting lens fragments are approximately $4-5 \mathrm{~mm}$ in diameter. To date, no peer-reviewed publications have documented the effect of tip diameter on phaco efficiency of varying lens sizes. Therefore, the use of a porcine $3 \mathrm{~mm}$ lens cube in this study would not only try to mimic clinically relevant lens fragment sizes but also test the idea that efficiency and chatter would be appreciably different with a larger fragment being emulsified, using various phaco tip sizes under continuous transversal and micropulse longitudinal US power.

We postulated that larger bore needles would be more effective at specified vacuum levels, due to their increased surface area. Furthermore, we hypothesized that use of larger bore needles would lead to an increase in material consumed for each cycle of tip movement; this would result in a decreased removal time of both the $2 \mathrm{~mm}$ and $3 \mathrm{~mm}$ lens cube regardless of phaco settings. Since the selected phaco parameters have a great deal of impact on efficiency as well as on chatter, we used the most efficient combination that had been found in previously reported studies. ${ }^{2,4-31}$

\section{Materials and Methods}

This in vitro research did not include human subjects or animals, and did not require approval by the University of Utah Institutional Review Board and Institutional Animal Care and Use Committee approval.

\section{Lens Preparation}

Porcine lenses obtained from Visiontech, Inc. (Sunnyvale, Texas, USA) were prepared as described in previous papers. $^{2,5-7}$ After dissection within 48 hours of arrival, each lens nucleus was soaked for two hours in $10 \mathrm{~mL}$ of $10 \%$ neutral-buffered formalin. Subsequently, for 24 hours all the nuclei were placed in $10 \mathrm{~mL}$ of balanced salt solution (BSS); this procedure increased uniformity of formalin hardening. A lens-cutting apparatus cut each lens into cubes that measured either $2.0 \mathrm{~mm}$ or $3.0 \mathrm{~mm}$, by the same person to reduce variability in lens fragment sizes. $^{2,4-7}$ These cubes were stored in a moisture chamber filled with BSS until the experiments were conducted, no more than 24 hours after the lenses were cut. These porcine lenses are comparable to both density and behavior of human cataracts during phaco. ${ }^{5}$ For random cube selection throughout each experiment, all the lens cubes were placed in a single container and frequently mixed.

\section{Phacoemulsification Settings}

The Whitestar machine (Abbott Medical Optics, Inc. Johnson \& Johnson Vision [J\&J], Santa Ana, California, USA) was used for these studies. We selected micropulse longitudinal US and continuous transversal US under settings already determined to be most efficient for $2 \mathrm{~mm}$ cubes. ${ }^{2,4,5,32}$ Longitudinal US was $50 \%$ power, micropulse $6 \mathrm{~ms}$ on-time cycle and $12 \mathrm{~ms}$ off-time cycle. Transversal US was set at $50 \%$ continuous power. Both US modalities used a $50 \mathrm{~cm}$ bottle height and $40 \mathrm{~mL} / \mathrm{min}$ flow rate, as well as $550 \mathrm{~mm} \mathrm{Hg}$ vacuum. In addition, both of the modalities made use of the peristaltic pump setting, which allows independent aspiration and level control, as previously described. ${ }^{2}$ US and vacuum remained at their maximum setting, with full pedal on.

\section{Phacoemulsification Tips}

To draw meaningful conclusions between our two lens fragment models, we used the Ellips FX handpiece $(\mathrm{J} \& \mathrm{~J})$, with tips that were similar to those used in our previous $2 \mathrm{~mm}$ porcine lens model studies. ${ }^{2,4-7}$ In this study, we used tips measuring $19 \mathrm{G}, 20 \mathrm{G}$, or $21 \mathrm{G}$ for both US modalities. However, the tips used during the continuous transversal US modality had a 30-degree bend and tips used during the micropulse longitudinal US modality were straight with no curvature.

\section{Efficiency and Chatter Comparisons}

We defined efficiency as the number of seconds used for lens fragment removal by US, and chatter as the number of lens-fragment repulsions that emanated from the tip. Comparisons were consistent with previously described methods. ${ }^{2,4,5}$ One randomly selected lens cube was placed in a rubber chamber that we filled with BSS. After the pedal was depressed and the lens fragment occluded the 
tip, the pedal was fully depressed so as to initiate US A stopwatch recorded the interval from US initiation to total fragment removal. If the cube dislodged from the phaco tip at any time during the duration of US, then the stopwatch was stopped. Any dislodgement was considered a chatter event. Whenever a particle dislodged from the tip, the pedal again was depressed to vacuum, until it was aspirated to the tip. After the particle re-occluded the tip, the pedal was fully depressed to the US setting, and we resumed the timing process, thereby allowing distinction of chatter delay time from total particle removal time.

\section{Statistical Analysis}

After efficiency times were averaged, the standard deviation (SD) was calculated. Efficiency times greater than 2 SDs from the mean were designated as outliers and taken out of the data set. Our rationale for excluding these data points is based on previous studies, in which we observed cases of microchatter that led to emulsification times, which were sufficiently long that they skewed the results. ${ }^{2,4,6,7,23}$ Therefore, we removed these outlier data points from all analyses to optimally interpret the results of our experiments.

We calculated the modified means and SDs, and used a paired Student's $t$-test to compare efficiency times between tip diameters for each US variation or a multivariable regression to evaluate the variables that predicted phacoemulsification performance assessed by removal time or chatter events; significance was set at $P<0.05$. Stata-17 software (StataCorp LLC, College Station, TX, USA) was used for analyses.

\section{Results}

\section{Influence of Lens Size and Phaco Tip Diameter on Phaco Efficiency}

The lens removal time increased as tip size decreased with all US systems, regardless of lens fragment size (Figure 1). These differences achieved statistical significance between the 19 and $21 \mathrm{G}$ tips, with micropulse longitudinal US, using the $2.0 \mathrm{~mm}$ cube (2.0 seconds \pm 1.26 [SD] versus 3.1 seconds \pm 1.84 [SD]; $P=0.04$ ) (Figure $1 \mathrm{~A}$ ) and the $3.0 \mathrm{~mm}$ lens cube (6.8 seconds \pm 3.62 [SD] versus 11.4 seconds \pm 5.61 [SD]; $P=0.005$ ) (Figure 1B), and also with continuous transversal US using the $2.0 \mathrm{~mm}$ cube $(1.2$ seconds \pm 0.51 [SD] versus 1.8 seconds \pm 0.84 [SD]; $P=0.01$ ) (Figure 1C) and the $3.0 \mathrm{~mm}$ lens cube (4.0 seconds \pm 1.77 [SD] versus 6.3 seconds $\pm 2.79[\mathrm{SD}] ; P=0.005$ ) (Figure 1D). In addition, there was a statistically significant decrease in emulsification time between the 20 and $21 \mathrm{G}$ tips with the micropulse longitudinal US system using the $2.0 \mathrm{~mm}(2.0$ seconds $\pm 1.20[\mathrm{SD}]$ versus 3.1 seconds $\pm 1.84[\mathrm{SD}$ ]; $P=0.03)$ and the $3.0 \mathrm{~mm}$ lens cube (7.1 seconds \pm 4.10 [SD] versus 11.4 seconds $\pm 5.61[\mathrm{SD}] ; P=0.01)$. No statistically significant difference was noted in $2 \mathrm{~mm}$ lens removal times between $19 \mathrm{G}$ and $20 \mathrm{G}$ tip, regardless of US system. However, there was a statistically significant emulsification time decrease for the $3 \mathrm{~mm}$ lens fragment using the $19 \mathrm{G}$ tip in the continuous transversal US system when compared to the $20 \mathrm{G}$ tip (4.0 seconds \pm 1.77 [SD] versus 5.8 seconds $\pm 2.88[\mathrm{SD}] ; P=0.02$ ) (Figure $1 \mathrm{D}$ ). Combining all US studies, the average lens removal time for a $3 \mathrm{~mm}$ lens cube was significantly longer $(P<0.0001)$ compared to a $2 \mathrm{~mm}$ lens cube regardless of the US system used. In addition, the $19 \mathrm{G}$ tip had the most efficient removal time regardless of lens fragment size as well as US system. We then used the removal times for both lens cube sizes using the three needle bores, for the micropulse longitudinal trials (Table 1) and for the continuous transversal trials (Table 2), excluding outliers, to generate a multivariable regression model. To generate this model, we treated phacoemulsification system as a binary variable by assigning a value of 0 for the micropulse longitudinal setting and 1 for the continuous transversal setting. The model accounted for $\sim 50 \%$ of the variance and included the following variables: phaco settings, needle bore diameter, and lens size (Table 3 ). The most significant predictor of removal time was lens size $(P<0.001)$.

\section{Influence of Lens Size and Tip Diameter on Chatter Incidence}

No statistically significant differences in chatter were present when emulsifying a $2 \mathrm{~mm}$ lens fragment in micropulse longitudinal US and when emulsifying a $3 \mathrm{~mm}$ lens fragment in continuous transversal US, regardless of the tip diameter (Figure 2). However, when using the $19 \mathrm{G}$ tip, a statistically significant increase in chatter events was observed when emulsifying a $3 \mathrm{~mm}$ lens cube in the micropulse longitudinal US setting compared to the $2 \mathrm{~mm}$ lens cube $(P=0.02)$. The chatter events for the three needle bores for the micropulse longitudinal trials (Table 1) and for the continuous transversal trials (Table 2), excluding outliers, were used to generate a regression model to predict the likelihood of a chatter event. To generate this model, we treated chatter events as a binary variable in which we 

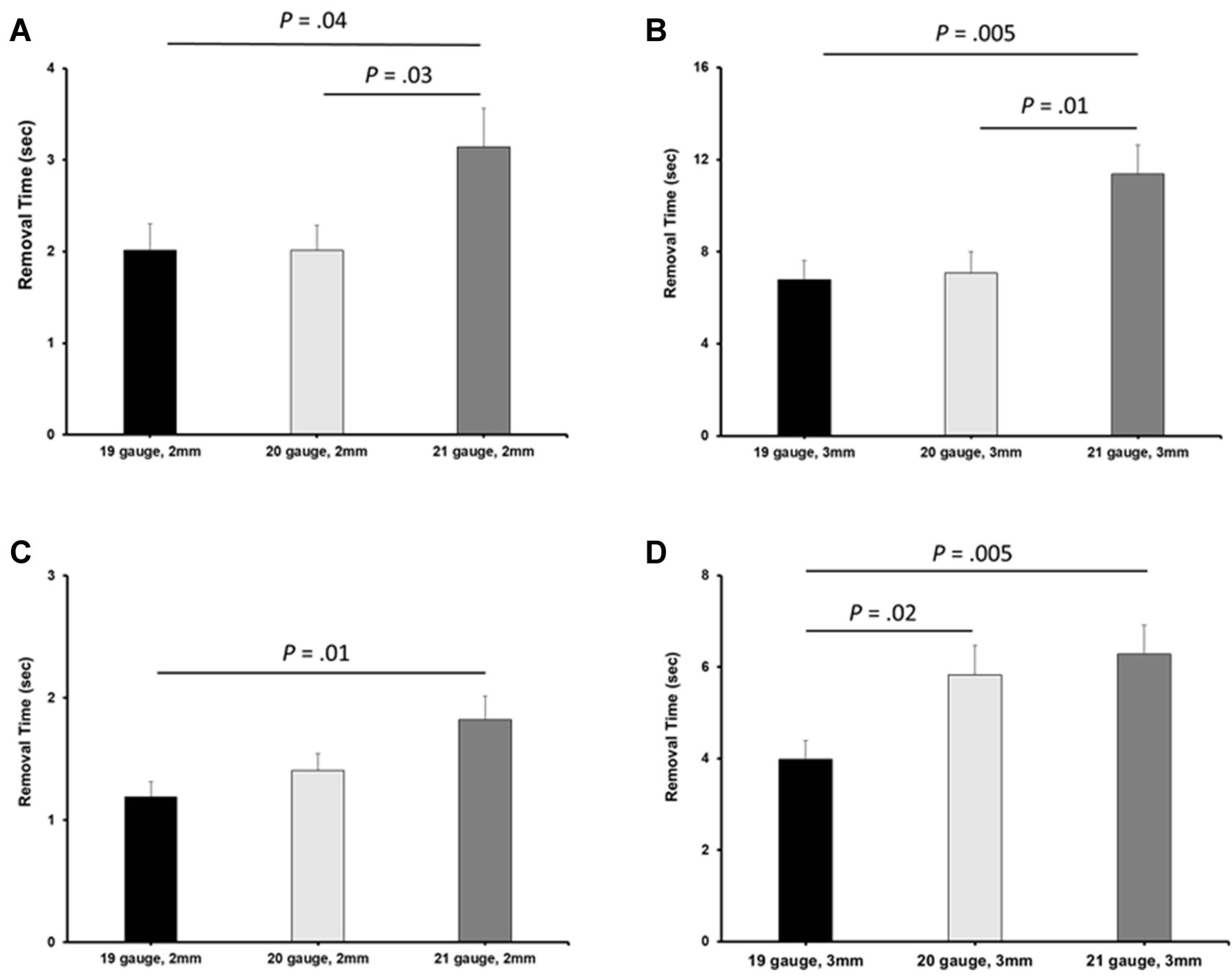

Figure I Comparison of mean removal time for complete phacoemulsification of $2 \mathrm{~mm}$ or $3 \mathrm{~mm}$ porcine lens model between the two phacoemulsification systems. Mean removal times were plotted as a function of tip diameter from (A) micropulsed longitudinal US using a 2 mm porcine lens cube, (B) micropulsed longitudinal US using a $3 \mathrm{~mm}$ porcine lens cube, (C) continuous transversal US using a $2 \mathrm{~mm}$ lens cube, and (D) continuous transversal US using a $3 \mathrm{~mm}$ lens cube (the two-sample $t$-test was not adjusted for chatter). The error bars represent the standard error of the mean.

assigned a value of 0 when we observed no chatter events and a value of 1 when we observed 1 or more chatter events. We also treated phacoemulsification system as a binary variable by assigning a value of 0 for micropulse longitudinal and 1 for continuous transversal. The model only accounted for $\sim 6 \%$ of the variance and included the following variables: phaco setting, needle bore diameter, and lens size (Table 4). The most significant predictor of a chatter event occurring was lens size $(P<0.01)$.

\section{Discussion}

Varying tip diameters and the ability to manipulate vacuum, aspiration, and irrigation flow rates allow the user to customize settings for optimal lens removal. Poiseuille's equation states that flow is directly proportional to the tube radius to the 4th power. Minor bore diameter changes lead to a significantly large flow rate alteration. In order to preserve the flow rate using a smaller bore needle, pumps work harder to maintain flow, ${ }^{1}$ creating a potential rate limiting step for smaller bore tips. Additionally, as the size of the fragment increases, more lens material potentially needs to be cleared by the phaco tip. Taken together, these limitations make smaller bore needles less effective in clearing larger fragments and denser cataracts.

Another variable in phacoemulsification is the ability to hold fragments through vacuum. Vacuum is conditionally directly proportional to the bore radius square of a system, with higher vacuum levels corresponding to improved efficiency in our previous studies. ${ }^{6,8,22-24}$ As such, an increased tip size should be favored as vacuum has an effect on the removal speed of lens particles through a compressive force exerted on the piece, thereby 


\begin{tabular}{|c|c|c|c|}
\hline$\frac{\bar{N}}{2}$ & 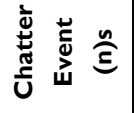 & $0000-000000-00000000$ & \\
\hline 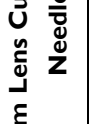 & 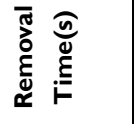 & 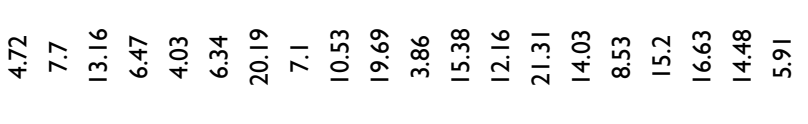 & $\stackrel{+}{=} \overline{0}$ \\
\hline & & 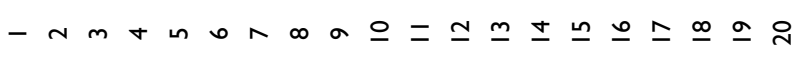 & 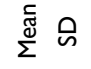 \\
\hline$\frac{0}{i}$ & 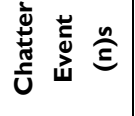 & 00000000000000000000 & \\
\hline 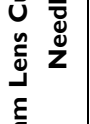 & 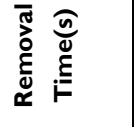 & 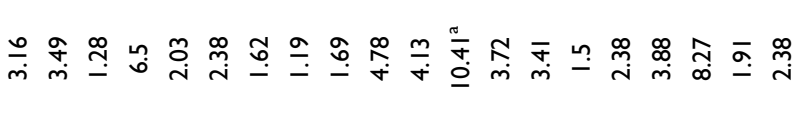 & $\bar{m} \stackrel{\square}{-}$ \\
\hline & & 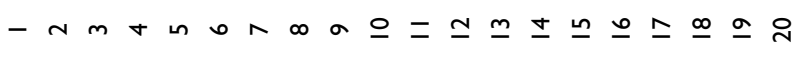 & $\stackrel{\text { ฮ్ల }}{\Sigma}$ 怘 \\
\hline ن & 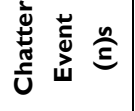 & $0000000000000-000000$ & \\
\hline 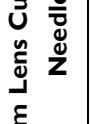 & 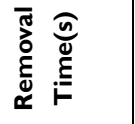 & 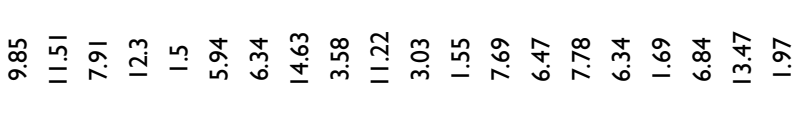 & $\bar{r} \frac{0}{\dot{r}}$ \\
\hline & & 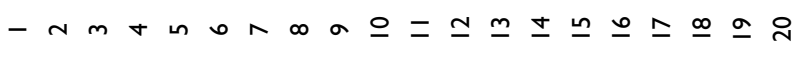 & $\stackrel{\text { ฮ్ }}{\Sigma}$ 怘 \\
\hline ن & 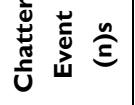 & 00000000000000000000 & \\
\hline 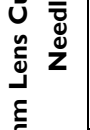 & 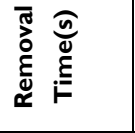 & 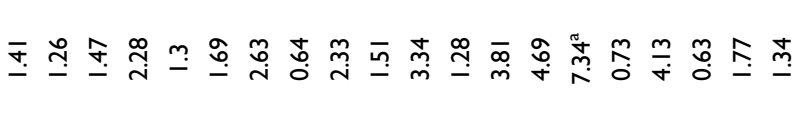 & 오 꼬 \\
\hline & & 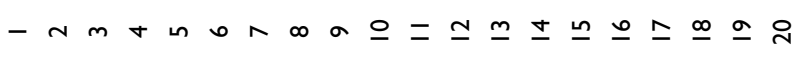 & 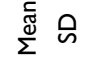 \\
\hline $\begin{array}{l}0 \\
a \\
0 \\
0\end{array}$ & 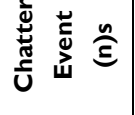 & $0-0000-0 n-0000000-10$ & \\
\hline 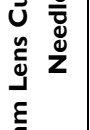 & 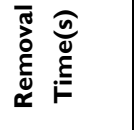 & ô & $\stackrel{\infty}{\infty} \underset{0}{\stackrel{n}{m}}$ \\
\hline & & 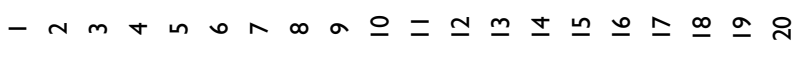 & 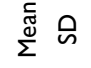 \\
\hline & 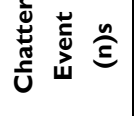 & $000000000-00000000-0$ & \\
\hline 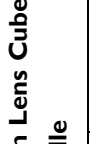 & 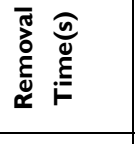 & 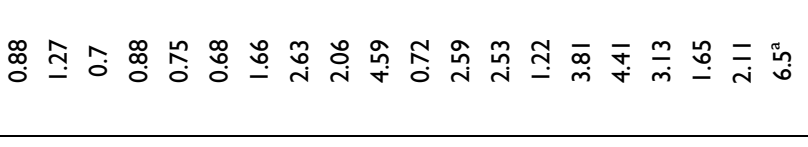 & 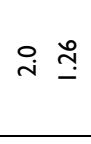 \\
\hline 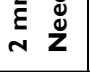 & & 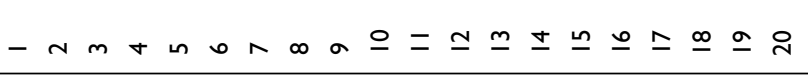 & $\stackrel{\sqrt[్]{\varpi}}{\Sigma}$ 岕 \\
\hline
\end{tabular}




\begin{tabular}{|c|c|c|c|}
\hline$\frac{\bar{N}}{0}$ & 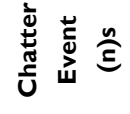 & $-000-100000000000-00$ & \\
\hline 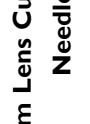 & 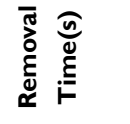 & 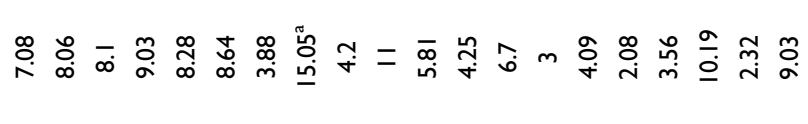 & $\underset{0}{\stackrel{m}{i}}$ \\
\hline & & 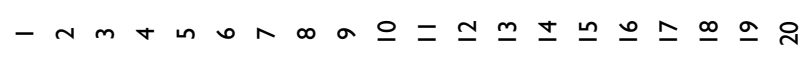 & 忍 \\
\hline$\frac{\bar{N}}{0}$ & 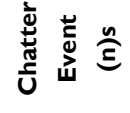 & $00000-00000000000000$ & \\
\hline 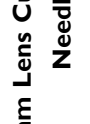 & 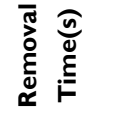 & 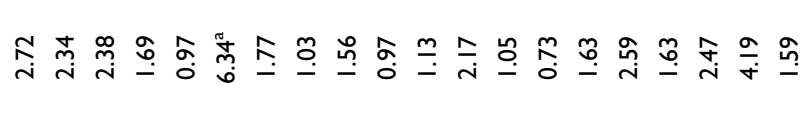 & $\stackrel{\infty}{\stackrel{\infty}{\infty}} \underset{0}{\infty}$ \\
\hline & & 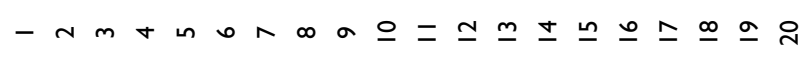 & 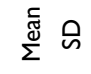 \\
\hline $\begin{array}{l}\text { i } \\
0 \\
0\end{array}$ & 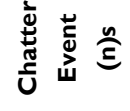 & $00-000--00-00-00-000$ & \\
\hline 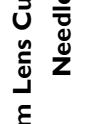 & 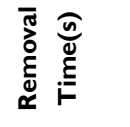 & 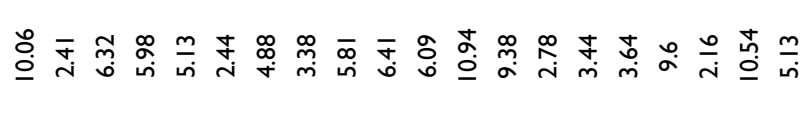 & $\stackrel{\infty}{\infty} \stackrel{\infty}{\infty} \underset{i}{\infty}$ \\
\hline & & 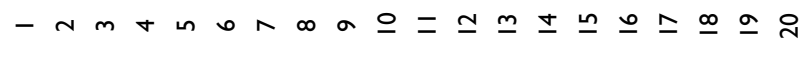 & 胥 \\
\hline i & 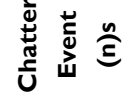 & 00000000000000000000 & \\
\hline 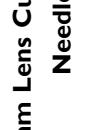 & 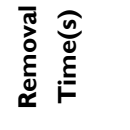 & 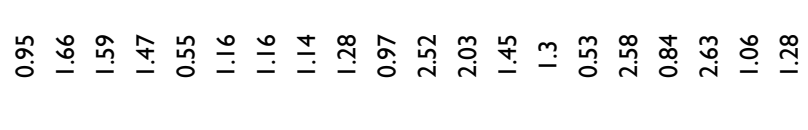 & $\stackrel{-0}{ \pm 0}$ \\
\hline & & 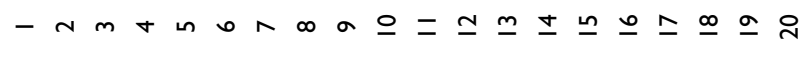 & 胥 \\
\hline$\underline{0}$ & 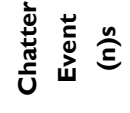 & $00000-00000000000000$ & \\
\hline 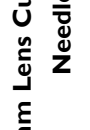 & 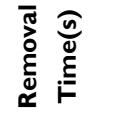 & 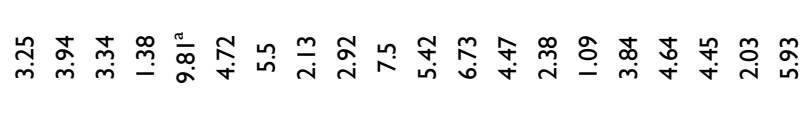 & $\stackrel{+}{\uparrow}$ \\
\hline & & 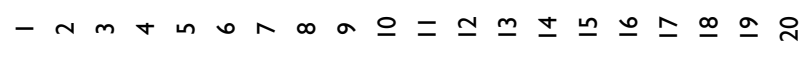 & 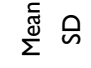 \\
\hline & 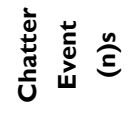 & $0000000-00 n-00000000$ & \\
\hline 选 & 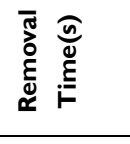 & 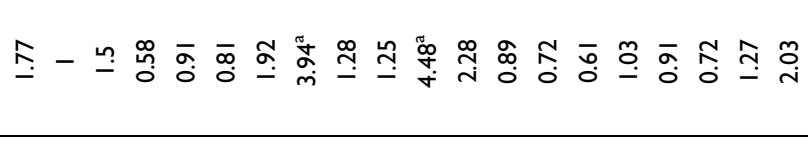 & $\stackrel{n}{\simeq}$ \\
\hline 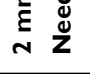 & & 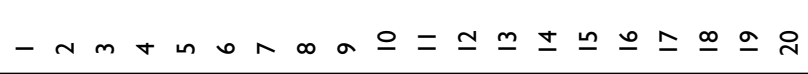 & 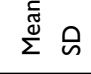 \\
\hline
\end{tabular}


Table 3 Final Multivariable Regression Model (Dependent Variable, Removal Time)

\begin{tabular}{|c|c|c|c|c|c|}
\hline Model & $\mathbf{R}^{2}$ & Predictor Variables & Coef. $^{a}$ & Std. Err. ${ }^{b}$ & t value \\
\hline Final & 0.498 & $\begin{array}{c}\text { Constant } \\
\text { Phacoemulsification System } \\
\text { Needle Bore Diameter } \\
\text { Lens Size }\end{array}$ & $\begin{array}{c}-2.004 \\
1.105 \\
4.976\end{array}$ & $\begin{array}{l}0.378 \\
0.233 \\
0.378\end{array}$ & $\begin{array}{l}-6.12 \\
-5.31 \\
4.75 \\
13.18\end{array}$ \\
\hline
\end{tabular}

Notes: ${ }^{a}$ Coefficient; ${ }^{\text {b }}$ Standard error.

ensuring that the piece is in contact with the tip during US delivery. However, extreme levels of vacuum pose a risk when inadvertent contact with delicate ocular tissues is more likely to occur secondary to the increased postocclusion surge.

In our previous work on tip bore, we found a statistically significant improvement in fragment removal with a $20 \mathrm{G}$ tip compared to a $21 \mathrm{G}$ tip. There were no significant advantages to a $19 \mathrm{G}$ tip compared to either a $20 \mathrm{G}$ or a $21 \mathrm{G}$ tip; however, the data demonstrated trends that favored the $20 \mathrm{G}$ tip over the $19 \mathrm{G}$ tip. ${ }^{2} \mathrm{We}$ hypothesized that there may be a relationship between the fragment size and the tip bore which could limit the efficiency benefit of a larger bore tip using $2 \mathrm{~mm}$ lens
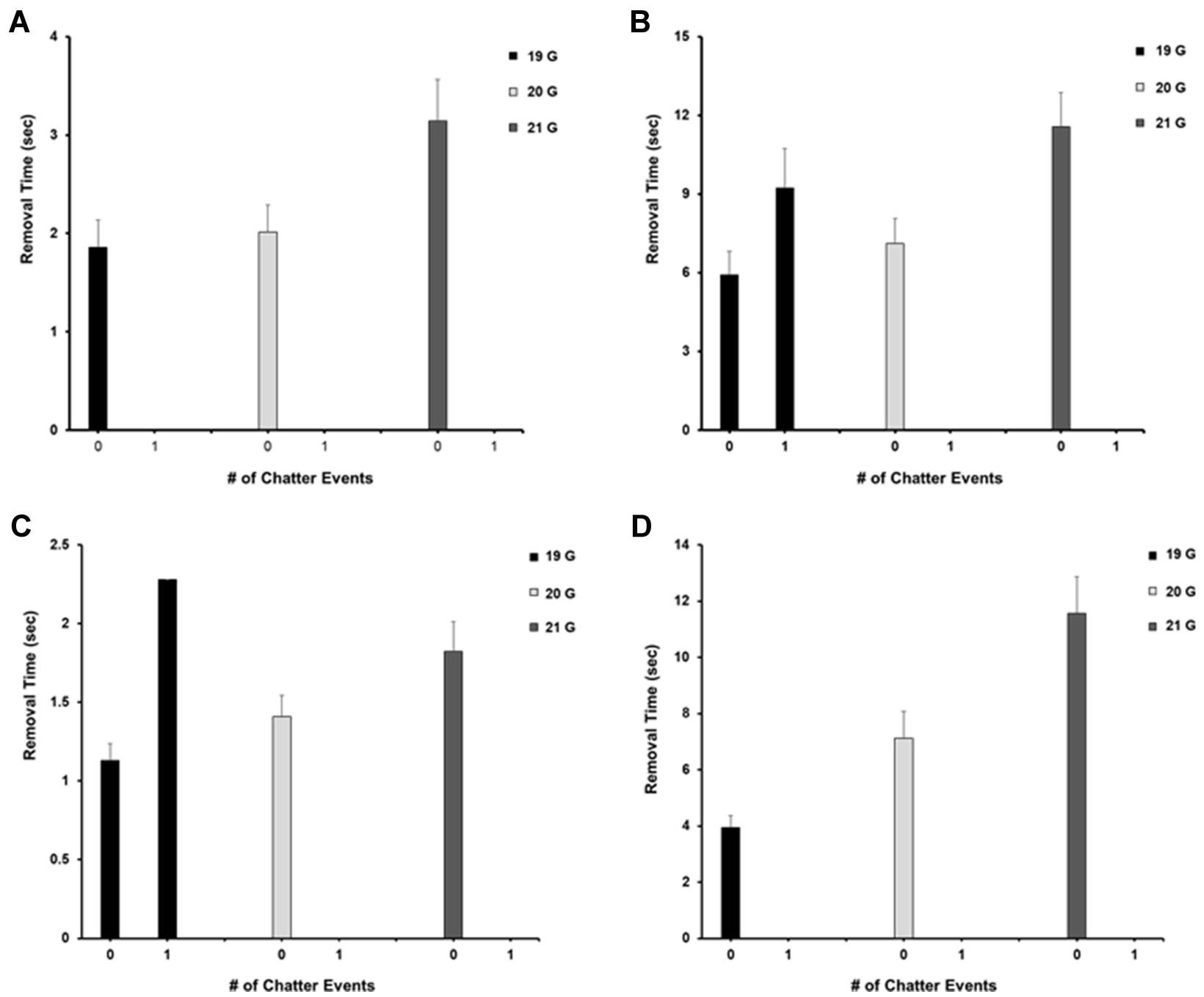

Figure 2 Effect of tip size on the number of chatter events for $2 \mathrm{~mm}$ and $3 \mathrm{~mm}$ lens cubes. Mean removal times were plotted as a function of the number of chatter events for a given tip diameter from (A) micropulsed longitudinal US using a $2 \mathrm{~mm}$ porcine lens cube, (B) micropulsed longitudinal US using a $3 \mathrm{~mm}$ porcine lens cube, (C) continuous transversal US using a $2 \mathrm{~mm}$ lens cube, and (D) continuous transversal US using a $3 \mathrm{~mm}$ lens cube. The error bars represent the standard error of the mean. 
Table 4 Final Multivariable Regression Model (Dependent Variable, Chatter Events)

\begin{tabular}{|l|c|c|c|c|c|}
\hline Model & $\mathbf{R}^{\mathbf{2}}$ & Predictor Variables & Coef. $^{\mathbf{a}}$ & Std. Err. $^{\mathbf{b}^{\mathbf{2}}}$ & t value \\
\hline \multirow{2}{*}{ Final } & \multirow{2}{*}{0.058} & Constant & & & 0.34 \\
& & Phacoemulsification System & 0.019 & 0.023 & 0.5 \\
& & Needle Bore Diameter & -0.021 & 0.038 & -0.9 \\
& & Lens Size & 0.136 & 0.477 & 3.6 \\
\hline
\end{tabular}

Notes: ${ }^{a}$ Coefficient; ${ }^{b}$ Standard error.

cubes. This theory was a driving force behind the work performed in this study. The current study corroborated our theory that no superiority was seen by use of the 20 $\mathrm{G}$ tip over the $19 \mathrm{G}$ tip, particularly with the larger $3 \mathrm{~mm}$ lens cubes with respect to phaco efficiency. In addition, with $3 \mathrm{~mm}$ cubes the $19 \mathrm{G}$ tip was more efficient versus the $20 \mathrm{G}$ tip using continuous transversal US. Taken together, our findings suggest larger bore tips provide greater advantages in phaco efficiency when removing larger lens fragments.

The data presented in this paper suggest similar trends for $3 \mathrm{~mm}$ and the $2 \mathrm{~mm}$ lens fragments. We did see that the difference for the $3 \mathrm{~mm}$ cubes in going from a $19 \mathrm{G}$ to a 20 $G$ needle was much larger than the same difference with $2 \mathrm{~mm}$ lens cubes, which does lend support to our original hypothesis. The main differences were the significantly longer duration required for removal of the $3 \mathrm{~mm}$ lens cube compared to the $2 \mathrm{~mm}$ cube. This is not surprising given the 3.4 times larger volume of lens material to be emulsified. In fact, the time ratio differences mirror the lens volume. This finding supports the clinical practice of reducing phaco energy usage through further lens debulking via chop or other mechanical techniques without worrying about lens fragment size.

Interestingly, there were significantly more chatter events when removing the $3 \mathrm{~mm}$ lens cube using a 19 $\mathrm{G}$ needle in micropulse longitudinal US compared to the $19 \mathrm{G}$ run with $2 \mathrm{~mm}$ pieces and to the $3 \mathrm{~mm}$ cube size with 20 and $21 \mathrm{G}$ tips. Evaluation of retained lens fragments following phacoemulsification via vitrectomy found that the vast majority of the retained fragments were at least $1 /$ 3 the size of the lens nucleus and that smaller lens fragments were found less often. ${ }^{33}$ The data from this study suggest that the largest bore size combined with the larger lens fragment creates a greater repulsion force in the straight longitudinal phaco and may explain why the larger lens fragments were retained and caused post-operative complications. It has long been noted, both clinically and in our previous work, ${ }^{2,4-7}$ that longitudinal forces contribute to chatter events. Previously, it was unknown whether the size of the tip and lens fragment is a significant variable affecting phaco efficiency.

The use of continuous transversal US showed similar but not identical findings to those observed with micropulse longitudinal US. For $2 \mathrm{~mm}$ pieces, as the needle size decreased, the removal time increased (ie, $19 \mathrm{G}<20 \mathrm{G}<$ $21 \mathrm{G})$ with no statistically significant difference between the $19 \mathrm{G}$ compared to $20 \mathrm{G}$, or $20 \mathrm{G}$ compared to 21 G. However, we did find a significant difference between the $19 \mathrm{G}$ and $21 \mathrm{G}$ needle. This was similar to our previous observation of greater efficiency with the $0.9 \mathrm{~mm}$ tip, compared to the $0.7 \mathrm{~mm}$ tip. $^{2}$

A similar pattern was seen when removing a $3 \mathrm{~mm}$ lens. The efficiency was highest when using the largest diameter needle, with $19 \mathrm{G}$ being significantly more efficient than 20 G. This finding was unexpected considering that the $3 \mathrm{~mm}$ piece-19 G experiments demonstrated significant chatter events observed with micropulse longitudinal US. Another unexpected finding emerged with the $2 \mathrm{~mm}-19 \mathrm{G}$ continuous transversal runs, which showed a significant number of chatter events compared to all other transversal runs with the $2 \mathrm{~mm}$ lens. Again, we observed a pattern of chatter events dependent on tip size, fragment size, and US modality. While the clinical relevance of these findings is uncertain, they reinforce the previously unknown and unpredictable nature of phaco variables on chatter events.

While this study was not intended to be a direct comparison between micropulse longitudinal and continuous transversal US, it is noteworthy that the latter was more efficient across all parameters. However, additional studies are needed to confirm this for other machine settings. Finally, it is possible that our series may have shown statistically significant differences with improved efficiency for larger tip sizes by powering the study with a larger number of runs for each setting. However, the trends remain consistent with previous work and with variable fragment size.

Limitations of our study include potential differences between hardened porcine lenses and human cataracts. We 
feel that our previous work correlated our experimental lenses with 3-4+ human cataracts. ${ }^{5}$ Additional limitations include that this study was an in vitro one. In a clinical setting, it would not be possible to study the effects of any phacoemulsification parameter on fragment size, given the variability of fragments encountered during surgery.

Overall, our data support the idea that further mechanical breakdown of a lens prior to using phaco to remove the fragment would be beneficial in clinical settings that utilize larger diameter needles; this may have relevance for femtosecond laser assisted cataract surgeries and techniques, such as phaco chop.

\section{Conclusion}

In summary, phaco is more efficient with larger tip diameters for relatively smaller and larger lens fragments. Understanding these previously unknown relationships between the variables tested here is an important step in determining the balance between efficiency of removal, wound size, and tissue safety.

\section{Abbreviations}

BSS, balanced salt solution; J\&J, Johnson \& Johnson Vision; phaco, phacoemulsification; SD, standard deviation; US, ultrasound.

\section{Data Sharing Statement}

Data supporting the results reported in the manuscript can be found at hive.utah.edu (https://hive.utah.edu/concern/ datasets/sn009x76k).

\section{Ethics Approval and Informed Consent}

Since no human subjects were involved, approval from the University of Utah Institutional Review Board was not obtained.

\section{Acknowledgments}

Susan Schulman assisted with writing and preparing the manuscript.

\section{Funding}

This study was supported in part by an unrestricted grant from Research to Prevent Blindness, Inc., New York, New York, USA, to the Department of Ophthalmology and Visual Sciences, University of Utah, Salt Lake City, Utah, USA.

\section{Disclosure}

Dr. Olson is on the Board of Directors of Perceive Bio and the Scientific Advisory Board of Perfect Lens. Dr. Jeff Pettey reports a Consulting agreement from Lensar, outside the submitted work. The other authors report no other conflicts of interest in this work.

\section{References}

1. Devgan U, Colvard DM, Beardsley TL, Bobrow JC, Isbey EKI. Basic principles of phacoemulsification and fluid dynamics. Am Acad Ophthalmol. 2010;28:1-10.

2. Farukhi AM, Stagg BC, Ronquillo C Jr, et al. Effect of phaco tip diameter on efficiency and chatter. J Cataract Refract Surg. 2014;40 (5):811-817.

3. Bobrow JC, Beardsley TL, Jick SL, et al. Anatomy: capsule. In: Cantor LB, Rapuano CJ, Cioffi GA, editors. Basic and Clinical Science Course 2014-2015 Lens and Cataract, Section 11. San Francisco: American Academy of Ophthalmology; 2015:7.

4. DeMill DL, Zaugg BE, Pettey JH, et al. Objective comparison of 4 nonlongitudinal ultrasound modalities regarding efficiency and chatter. J Cataract Refract Surg. 2012;38(6):1065-1071.

5. Oakey ZB, Jensen JD, Zaugg BE, et al. Porcine lens nuclei as a model for comparison of 3 ultrasound modalities regarding efficiency and chatter. J Cataract Refract Surg. 2013;39(8):1248-1253.

6. Gupta I, Cahoon JM, Gardiner G, et al. Effect of increased vacuum and aspiration rates on phacoemulsification efficiency. $J$ Cataract Refract Surg. 2015;41(4):836-841.

7. Stagg BC, Gupta I, Cahoon J, et al. Bent versus straight tips in micropulsed longitudinal phacoemulsification. Can J Ophthalmol. 2015;50(5):354-359.

8. Shi DS, Jensen JD, Kramer GD, et al. Comparison of vacuum and aspiration on phacoemulsification efficiency and chatter using a monitored forced infusion system. Am J Ophthalmol. 2016;169:162-167.

9. Boulter T, Jensen JD, Christensen MD, et al. Comparison of a torsional and a standard tip with a monitored forced infusion phacoemulsification system. J Cataract Refract Surg. 2016;42 (4):613-617.

10. Jensen JD, Shi DS, Robinson MS, et al. Torsional power study using CENTURION phacoemulsification technology. Clin Exp Ophthalmol. 2016;44(8):710-713.

11. Garff K, Jensen JD, Cahoon J, et al. Impact of micropulsed ultrasound power settings on the efficiency and chatter associated with lens-fragment removal. J Cataract Refract Surg. 2015;41(6):1264-1267.

12. Kirk KR, Ronquillo C Jr, Jensen JD, et al. Optimum on-time duty cycle for micropulse technology. J Cataract Refract Surg. 2014;40 (9): 1545-1548.

13. Gupta I, Zaugg B, Stagg BC, et al. Phacoemulsification efficiency with a radiused phaco tip. J Cataract Refract Surg. 2014;40 (5):818-821.

14. Gardiner GL, Garff K, Gupta I, et al. Effect of pulsing ultrasound on phacoemulsification efficiency. J Cataract Refract Surg. 2015;41 (11):2560-2564

15. Gilbert M, Zaugg B, Stagg B, et al. Safety profile of venturi versus peristaltic phacoemulsification pumps in cataract surgery using a capsular surrogate for the human lens. Am $J$ Ophthalmol. 2015;160(1):179-184.e1.

16. Jensen JD, Boulter T, Lambert NG, et al. Intraocular pressure study using monitored forced-infusion system phacoemulsification technology. J Cataract Refract Surg. 2016;42(5):768-771.

17. Jensen JD, Kirk KR, Gupta I, et al. Determining optimal ultrasound off time with micropulse longitudinal phacoemulsification. $J$ Cataract Refract Surg. 2015;41(2):433-436. 
18. Henriksen BS, Gardiner G, Garff K, et al. Thermal evaluation of two phacoemulsification systems. Can J Ophthalmol. 2016;51(1):14-18.

19. Boulter T, Christensen MD, Jensen JD, et al. Optimization and comparison of a $0.7 \mathrm{~mm}$ tip with the $0.9 \mathrm{~mm}$ tip on an active-fluidics phacoemulsification platform. $J$ Cataract Refract Surg. 2017;43(12):1591-1595.

20. Wright AJ, Thomson RS, Bernhisel AA, et al. Effect of chamber stabilization software on efficiency and chatter in a porcine lens model. J Cataract Refract Surg. 2017;43(11):1464-1467.

21. Wright DD, Wright AJ, Boulter TD, et al. Optimization of transversal phacoemulsification settings in peristaltic mode using a new transversal ultrasound machine. J Cataract Refract Surg. 2017;43 (9):1202-1206.

22. Cahoon JM, Gupta I, Gardiner G, et al. Comparison of venturi and peristaltic vacuum in phacoemulsification. J Cataract Refract Surg. 2015;41(2):428-432.

23. Ronquillo CC Jr, Zaugg B, Stagg B, et al. Determining optimal torsional ultrasound power for cataract surgery with automatic longitudinal pulses at maximum vacuum ex vivo. Am J Ophthalmol. 2014;158(6):1262-1266.e2.

24. Kabbara S, Heczko JB, Bernhisel AA, et al. Effect of high vacuum and aspiration on phacoemulsification efficiency and chatter using a transversal ultrasound machine. J Cataract Refract Surg. 2018;44 (11):1378-1383.

25. Kabbara S, Heczko J, Ta B, et al. Determining optimal ultrasound percent on time with long-pulse torsional phacoemulsification. Can J Ophthalmol. 2019;54(3):395-398.
26. Ha L, Wright A, Wright DD, et al. High vacuum and aspiration on phacoemulsification efficiency and chatter for centurion. Can J Ophthalmol. 2019;54(1):136-138.

27. Bohner AD, Wright AJ, Ta BT, et al. Optimum on-time duty cycle for a transversal ultrasound machine. J Cataract Refract Surg. 2018;44 (9):1140-1143.

28. Thomson RS, Bird BA, Stutz LA, et al. The effect of increasing power when grooving using phacoemulsification. Clin Ophthalmol. 2019;13:611-615.

29. Boulter T, Bernhisel A, Mamalis C, et al. Phacoemulsification in review: optimization of cataract removal in an in vitro setting. Surv Ophthalmol. 2019;64(6):868-875.

30. Bernhisel AA, Cahoon JM, Sella R, et al. Optimum on-time and off-time combinations for micropulse phacoemulsification in venturi vacuum mode. J Cataract Refract Surg. 2019;45(12):1797-1800.

31. Bohner A, Peterson JS, Wright AJ, et al. Effects on phacoemulsification efficiency and chatter at variable longitudinal ultrasound settings when combined with constant torsional energy. $J$ Cataract Refract Surg. 2020;46(5):774-777.

32. Kabbara SW, Heczko J, Ta B, et al. Impact of torsional micropulse on phacoemulsification efficiency and chatter. Can J Ophthalmol. 2019;54(5):560-564.

33. Moisseiev E, Kinori M, Glovinsky Y, Loewenstein A, Moisseiev J, Barak A. Retained lens fragments: nucleus fragments are associated with worse prognosis than cortex or epinucleus fragments. Eur J Ophthalmol. 2011;21(6):741-747.
Clinical Ophthalmology

\section{Publish your work in this journal}

Clinical Ophthalmology is an international, peer-reviewed journal covering all subspecialties within ophthalmology. Key topics include: Optometry; Visual science; Pharmacology and drug therapy in eye diseases; Basic Sciences; Primary and Secondary eye care; Patient Safety and Quality of Care Improvements. This journal is indexed on PubMed

\section{Dovepress}

Central and CAS, and is the official journal of The Society of Clinical Ophthalmology (SCO). The manuscript management system is completely online and includes a very quick and fair peer-review system, which is all easy to use. Visit http://www.dovepress.com/ testimonials.php to read real quotes from published authors. 